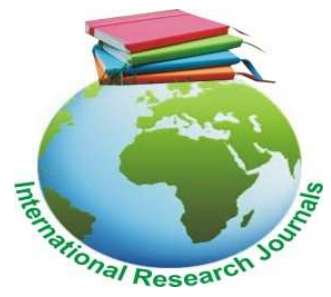

\title{
Learning environmental effects on reading and writing English Braille grade ii for the visually impaired child
}

\author{
${ }^{* 1}$ Zipporah Manoti Masea, ${ }^{2}$ Were Charles Michael, ${ }^{3}$ John Agak \\ ${ }^{1 / 2 / 3}$ Maseno University, P.O. Box 333, Maseno Kenya \\ ${ }^{*}$ Corresponding Author's E-mail:mmzipporah@gmail.com
}

\begin{abstract}
Learners with visual impairment (VI) depend on Braille as a medium of instruction and communication. According to a report by the Ministry of Education, only $45(30.6 \%)$ out of $147(100 \%)$ of learners with VI enrolled in upper primary classes in Kisumu and Siaya counties could read and write English Braille grade II competently. Despite this discrepancy, there was no documented explanation for this low percentage of learners with English Braille grade II competencies, particularly in Kisumu and Siaya Counties. The purpose of this study was to establish environmental challenges faced by learners with visual impairment in reading and writing of English Braille grade II, in selected Special Primary Schools in Kisumu and Siaya counties Kenya. The purpose of this study was to establish environmental challenges faced by learners with visual impairment in reading and writing of English Braille grade II, in selected Special Primary Schools in Kisumu and Siaya counties Kenya. Objective of the study was to; Establish Learner based challenges in acquiring and using English Braille grade II. Descriptive survey research design was adopted. The target population was 162 visually impaired learners and 54 teachers. Saturated sampling technique was used to select 147 visually impaired learners and 49 teachers. Data was collected by use of questionnaires and interview schedules. Test re-test method was used to determine the reliability coefficient of instruments at a score of 0.75 . Face and content validity of the research instruments was ascertained by experts from the department of Special Needs Education. Descriptive statistics such as frequency counts and percentages were used to analyze quantitative data. Qualitative data was transcribed, categorized into themes and sub-themes as they emerged. The findings revealed that these learners had negative attitude towards communication in English Braille Grade II. Only 26 (19.2\%) out of 147 of the learners were able to read and write English Braille Grade II. This study recommended early stimulation and introduction to Braille code for learners with VI; enforcement of functional educational inclusion to accommodate learners with VI and adoption of Individualized Educational Program (IEP). These findings will be of use to the Kenya Institute of Curriculum Development, Kenya National Examination Council, and Teacher Training Colleges for adapting the curriculum, on setting Examinations, and on how to train Teachers for Learners with visual impairment.
\end{abstract}

Keyword: Learning environment, Reading and Writing, Braille, Visually Impaired.

Background to the Study

According to Quigly (2000) a rich environment has a significant role to play in the reading and writing of English Braille grade II. Psychology of teaching and learning has shown that for any meaningful learning to take place, the learner must be supplied with all that can support learning including technology. There is little doubt 
that technology has changed the education of students with various impairments, as seen in many developed countries.

Two decades ago, the author's tools of the trade were Braillers and a tape recorder. Learners in schools also had this equipment and in a few instances; a

typewriter and a Dictaphone (a phone with Braille buttons). Currently, the range of electronic equipment for learners with Visual Impairment appears to be almost limitless, and their explosion in their availability increases exponentially. The smorgasbord of potential offered to learners with visual impairments is of enormous benefits.

There currently exists in both developed and developing countries a perception from both scholars and caretakers that the invention of technology in the reading and writing of Braille is likely to curtail the level and speed at which learners with visual impairment read and write Braille. On the contrary, teachers counter this view by arguing that technology or environment enrichment with new technology is likely to increase the level of literacy and rate of reading and writing English Braille grade II. Therefore, the researcher concurs with the teachers that invention of new technology is likely to increase the level of Braille literacy among learners with VI rather than decreasing it. For instance, the invention of the Braille phone called the Own phone, the World's first Braille phone. The London-based company employed 3D printing techniques to design the customizable phone. Both sides of the phone have a Braille keypad with two and four buttons that are preprogrammed to call specific individuals. For those not able to read Braille, the company can print raised text on the keypads which, through tactile feedback, can allow the user to interact with the devicehence, a clear indicator that the introduction of technology in education for the Blind (in the reading and writing of Braille) is a Braille booster in schools for learners with visual impairment.

The classroom has to have labels with words and embossed maps, diagrams and pictures everywhere, so that learners constantly connect written English with the things they represent. Teachers have to display these labels based on learners' needs and interests to provide children with disabilities support (Pressley, 2005).

Once learners reach Braille grade II, most of the information they need is given to them in a textual format where they focus changes from learning to read to and reading to learn. Therefore, those poor readers may have difficulty in interacting with the curriculum content freely.

There is a shortage of Braille materials and the methods of distributing the same are lacking. It has to be noted that scarcity of teachers who are supposed to instruct learners with visual impairment is also a setback to speed and fluency of reading and writing of Braille respectively. To counter this problem of inability to read and write Braille, the United States of America (USA) federal government decided to form the National Federation for the Blind (NFB) to enroll all those well- wishers who have interest of the American visually impaired.

These NFB members were to ensure that all the visually impaired learners who depend on Braille as a medium of communication, have an equal opportunity to access, and learn it effectively (Spungin, 2003).

Many Scholars and other concerned personnel on Braille standards look at teacher's caseload as a big influence to have the learners learn Braille. Many of such teachers attend to more than 6 learners per day which does not allow them to have adequate time to carry out individual instruction. Teachers have always attributed the inability to instruct Braille, to heavy caseload of them, therefore, argue that too much case load lower their competence. They suggest that the numbers of learners they attend to be reduced to four per day, an idea the administrators have rejected saying that this will transform many instructors into idlers (Frieman, 2004). In this case, the researcher disagrees with the administrator's view that reducing the teacher's caseload will transform them into idlers because it is a plain lie by the administrators due to their ignorance of the diverse needs of learners with visual impairment. Availability of print materials for learners with low vision as compared to the totally blind learners is also seen as hampering the reading and writing of English Braille grade II. Learners with VI who have total visual loss in some cases rely on those with Partial sight to read to them questions or notes from the chalkboard or reference material. Most educators insist that a choice must be made between print and Braille and that only one reading medium must be used. This disagreement translates in the field of disputes among professionals in planning meetings resulting in new deals to address individual learners. There are others who believe that inclusion is the main problem with reading and writing of English Braille. They argue that print materials in schools for learners with visual impairment are necessitated by the presence of learners with partial sight. Inclusion, as argued by many, is meant to reduce discrimination against those learners with $\mathrm{VI}$ and including them in the community of the sighted in order to enhance equal playing ground for all. Parents are not left out in this battle; they are often concerned about the best cause of action that they and their children become real victims in the academic battles especially when the parents of the sighted learners threaten to withdraw their children from learning centers (Fredeman, 2005). Despite the fact that different studies have been carried out on how environmental challenges influence learners with $\mathrm{VI}$ in reading and writing of English Braille grade II, no such study has ever been conducted in the lake region. Learners lacking previous know-how skills such as pre-Braille activities, alphabetic principles, and phonemic awareness need supplementary instruction to ensure they do not lag behind their sighted peers. Therefore, elementary school teachers must provide an element that allows learners with (VI) to 
access experiences they may have missed in their preschool period time (The National Reading Panel, 2001).With this in mind, the current study therefore sought to fill the gap by finding out the effect of environment on reading and writing English Braille grade II in the two special primary schools in Kisumu and Siaya counties, Kenya.

\section{Statement of the Problem}

Learners with visual impairment depended on Braille as a medium of instruction and communication. According to the report by the ministry of education, Kisumu and Siaya counties combined had the highest number (1232) of learners with visual Impairment (VI) in Kenya. Information from Kisumu and Siaya counties indicated that only $30.6 \%$ out of 147 learners enrolled in upper primary classes could read and write English Braille grade II competently. The low percentage could be attributed to certain challenges faced by learners with $\mathrm{VI}$ in reading and writing English Braille grade II in Kisumu and Siaya counties. Despite wide difference, there was no explanation for the low percentage of learners who could read and write English Braille grade II in Kisumu and Siaya counties.It was therefore for this reason that the researcher in this study sought to establish learning environment effect on reading and writing English Braille Grade II for the visually impaired child in special primary schools in Kisumu and Siaya counties.

\section{Purpose of the Study}

In consideration to the foregoing problem statement, the purpose of this study was to establish environmental challenges faced by learners with visual impairment in reading and writing of English Braille grade II, in selected Special Primary Schools in Kisumu and Siaya counties Kenya.

\section{Objective of the Study}

This study was guided by the following objective:

$i$ to examine environment based challenges faced by learners with visual impairment in reading and writing of English grade II.

\section{Assumptions of the Study}

The study was based on the assumption that all teachers in special schools for learners with visual impairment were competent in Braille reading and writing, there was a structured program on the development of Braille reading and writing, and finally, all learners with visual impairment have a chance to undertake Braille reading and writing.

\section{Scope of the Study}

The study focused on challenges faced by learners with visual impairments in Braille reading and writing particularly in selected special primary schools for learners with VI, in Kisumu and Siaya counties. The study was carried out in two special primary schools in Kisumu and Siaya counties namely: St. OdaAluor and Kibos School for the blind. It involved a total sample size of 198 people comprising 2 head teachers, 49 teachers, and 147 learners with total visual loss, thus relied entirely on Braille as medium of instruction and communication.

\section{Limitation of the Study}

Eight (16\%) teachers and twelve (8\%) learners did not return questionnaires. This margin is however rather too small to significantly affect the generalizability of the results obtained, considering that a large sample was drawn from a population with even greater diversity.

The assumption of the study that, all teachers in $\mathrm{VI}$ schools were Braille competent, turned out a fallacy, but also posing minimal impact; it fairly slowed down the data collection process hence prompting an extra day to finish up the task.

Limitations arising from time and financial resources were well put under check by sourcing for a research assistant and finances upfront, plus burning mid-night oil.

\section{Significance of the Study}

Overcoming the aforementioned research limitations was critical considering the tremendous benefits this study brings in the education for Learners with VI. The study findings could be significant to among others: Kenya Institute of Curriculum Development (KICD) would receive critical information that would help in adapting the curriculum for learners with visually impairment.The Kenya National Examination Council could get information vital in adaptation of examination questions for learners with visual impairment.

\section{RESEARCH METHODOLOGY}

\section{Research Design}

This study employed descriptive survey research design to find out challenges faced by learners with visual impairment in reading and writing English Braille grade II in special Primary Schools in Kisumu and Siaya countries 
Masea et al. 011

Table 1. Population and Sample Frame

\begin{tabular}{llll}
\hline Category of Respondents & Target population & Sample selected & Percentage \\
\hline Teachers & 54 & 49 & 90.74 \\
Learners & 162 & 147 & 90.74 \\
\hline
\end{tabular}

The descriptive survey research design involves collection of data from a sample of a population with respect to one or more variables (Best and Kahn, 2006). This design was more reliable in giving desired information and answers to the research questions under study, through the purposefully designed questionnaires and interview schedules. This was premised on the fact that an ideal sample population gives information about the whole population. Survey design is also advantageous because it is simple and easy to administer; because questionnaire, "allows collection of accurate information in a relatively shorter period of time" (Nyewebi, 2009). The use of descriptive survey design enabled the researcher to access accurate information easily, seek opinions, describe, analyze, and interpret information easily and clearly. It's appropriately linked research concepts and questions with the study, thus making it the most ideal design and more particularly for the area of study in question.

\section{Area of Study}

This study was conducted in Kisumu and Siaya counties in the lake regionLake Region is bordered by Rift valley to the North East, Western region to the West. Lake Region is the $5^{\text {th }}$ largest region in Kenya. Kisumu and Siaya counties have a total of 9 special schools namely: Joyland Special, School kibos School for the Blind, Lutheran Special Sch for MH, Maseno School for the Deaf, MasenoSch for the Deaf Blind, Maseno Mixed Special Unit, Equator-round Special school, St. Oda School for the Blind, Nyangoma School For Deaf out of which only two schools are for the visually impaired learners, one in each of the counties. The study was therefore carried out in two selected Special primary schools for the VI, Kibos School for the Blind in Kisumu County and St. Oda school for the blind primary in Siaya County.

\section{Study Population}

The study was carried out in two special primary schools for learners with $\mathrm{VI}$ in the lake region namely: Kibos
School for the blind and St. OdaAluor. The target population was 162 learners who were visually impaired and 54 teachers.

\section{Sample and Sampling Techniques}

Saturated sampling was used to select 147 learners, 49 teachers. It is worth noting that among the 49 teachers who were sampled, some were teaching other subjects apart from Braille as a subject (Table 1).

\section{Instruments of Data Collection}

The study used questionnaire, interview, and lesson observation schedules as the tools of data collection. These instruments were selected with regard to the information to be collected, time available and objectives of the study.

The questionnaireis the best suited for the study as it can be administered to a large population of respondents in a short period of time with not extra personnel (Creswell, 2003). The use of questionnaire allowed the researcher to explore areas of questioning to the respondent to get first-hand information about the objectives of the study. Three types of the questionnaires were used for head teachers, teachers, and the learners.

\section{Teachers and Learners Questionnaires}

For teachers the questionnaire was divided into three sections. Section A of the questionnaire contained questions on attitude, section $B$ contained questions on school environment, section $C$ contained questions on teacher's competence, and finally, section D contained questions on complexity of the Braille code as shown in appendix $A$ and $B$ respectively.

For learners' questionnaire, section $A$, contained question on Braille code, section $B$, questions on reading words written in Braille grade II, and section $\mathrm{C}$, was dictation on writing using Braille grade II as shown in appendix $\mathrm{C}$, section $\mathrm{C}$. All learners in upper primary were tested on basic Braille grade II to ascertain their ability to 
read and write English Braille grade II material, since it is the standard grade of Braille recommended for upper primary classes.

\section{Validity of the Research Instruments}

After pre-testing, the research instruments were presented to experts in the department of Special Education, Maseno University, who were conversant with the topic of study. The recommendations made were used to correct the observed errors before the questionnaires were administered in the field for data collection after thorough validation by the experts. Face and content validity were used to verify the accuracy of the research instruments used in the study.

\section{Reliability of the Research Instruments}

Reliability of the research tools in this study was established through test-retest. Pearson's product moment correlations revealed a high positive significant relationship for the learner's questionnaires, 0.75 , at $p$ value of 0.05 as recommended by Best and Kahn (2006).

\section{Data Collection Procedures}

Research permit was obtained from the Ministry of Education Science and Technology (M.O.E.S.T) through the school of graduate studies Maseno University. A courtesy call at the County Director of Education office, Sub- County Director of Education Officer's Office and the head teachers' offices in the two counties was thereafter done. Schools were then visited by the researcher to carry out classroom observation interviews and to distribute the questionnaires. For learners' questionnaire, the researcher with the help of research assistants guided the learners to fill the questionnaire in a single sitting, during which the researcher monitored the task to ensure no consultations were done among the learners.

\section{Data Analysis}

Data was organized using descriptive statistics which included frequency counts, means, percentages, standard deviations among others. Classroom observations on the challenges faced by learners with visual impairment in reading and writing English Braille grade II was put in tallies and frequencies.

Quantitative data was collected using questionnaires and analyzed using descriptive statistics in form of frequency counts, percentages, and means. In scoring the Likert scale scores, positive statements was awarded as follows: Strongly agree (SA)- 5 points, Agree (A)-4 points, Undecided (U)- 3 points, Disagree (D)- 2 points and Strongly Disagree (SD)-1 point.

In the interpretation of the scores above three implied positive attitude, while a score of three implied a neutral attitude while that below three implied negative attitude. Pearson Product Moment Correlation was carried out to determine the relationship between performance in reading English Braille grade II and attitude, the environment, Braille code based challenges.

\section{RESULTS AND DISCUSSION}

\section{Environmental Challenges}

In order to find out the Environment based challenges faced by learners with $\mathrm{VI}$ in reading and writing of Braille Grade II in special primary schools, teachers were asked to share their opinions on the same. Among the factors considered were the number of teachers, teacher-pupil ratio, usage of computers, story books in Braille in the school library, use of teaching aids and the mutual relationship among learners.

The results are presented as shown in table 2.

From the results in table 2, majority of the teachers, $27(65.8 \%)$ of the sampled respondents disagreed that in this school learners use computers and typewriters and that learner's ratio to that of teachers is over 10:1 as perceived by ( $58.5 \%$ ) of the teachers. In addition, the school did not have competent teachers to teach English Braille grade II, and there were few story books in Braille, $(39.0 \%)$ most of them observed. The findings also revealed that the schools did not have enough ramps and pathways as revealed by (53.6\%) of the teachers, $(34.1 \%)$ and $(19.5 \%)$ strongly disagreed and disagreed respectively. The overall results show that the school environment did not favor learners' instruction and communication in English Braille grade II. This study agree with previous studies such as (Pressley, 2005) which concluded that classroom has to have labels with words and pictures everywhere so that learners constantly connect written language with

The things they represent, teachers have to display these labels based on learners' needs and interests to provide children with disabilities support in the classroom (Pressley, 2005).

In addition, Frieman (2004) found out that many Scholars and other concerned personnel about the Braille standards look at teacher's caseload as a big influence to have the learners learn Braille. Many of such teachers attend to more than 6 learners per day which does not allow them to have adequate time to carry out individual instruction. Teachers have always attributed that inability to instruct Braille to heavy case load, teachers, therefore, argue that too much case load work down their competence. 
Table 2. Learning Environment

\begin{tabular}{|c|c|c|c|c|c|c|}
\hline \multirow[t]{2}{*}{ Learning environment } & SD & D & $\mathbf{U}$ & A & SA & MEAN \\
\hline & F (\%) & F (\%) & F (\%) & F (\%) & F (\%) & \\
\hline $\begin{array}{l}\text { In this school, learners have enough } \\
\text { materials for reading and writing } \\
\text { Braille }\end{array}$ & $10(24.4)$ & $20(48.80)$ & $1(2.40)$ & $8(19.50)$ & $2(4.9)$ & 2.3 \\
\hline $\begin{array}{l}\text { In this school, there are enough } \\
\text { teachers who teach Braille }\end{array}$ & 3.(7.3) & $21(51.2)$ & $3(7.3)$ & $6(14.6)$ & $8(19.5)$ & 2.9 \\
\hline $\begin{array}{l}\text { In this school learner's ratio to that of } \\
\text { teachers is over } 10: 1\end{array}$ & $15(36.6)$ & $11(26.8)$ & $3(7.3)$ & $3(7.3)$ & $9(22.0)$ & 2.4 \\
\hline $\begin{array}{l}\text { in this school learners use computers } \\
\text { and typewriter }\end{array}$ & $14(34.1)$ & 13(31.7) & $2(4.9)$ & $10(24.4)$ & $2(4.9)$ & 2.3 \\
\hline $\begin{array}{l}\text { This school has enough storybooks in } \\
\text { Braille in the library }\end{array}$ & $9(22.0)$ & $16(39.0)$ & $2(4.9)$ & $8(19.5)$ & $6(14.6)$ & 3.0 \\
\hline $\begin{array}{l}\text { Teachers in this school use teaching } \\
\text { aids during Braille lessons }\end{array}$ & $8(19.5)$ & $14(34.1)$ & $4(9.8)$ & $10(24.4)$ & $5(12.2)$ & 2.8 \\
\hline $\begin{array}{l}\text { this school support services are } \\
\text { offered to learners who read and write } \\
\text { using Braille }\end{array}$ & $9(22.0)$ & 12(29.3) & $5(12.2)$ & 13(31.7) & $2(4.9)$ & 2.7 \\
\hline $\begin{array}{l}\text { In this school, all teachers are } \\
\text { competent to teach Braille }\end{array}$ & $11(26.8)$ & $15(36.6)$ & $3(7.3)$ & $6(14.6)$ & $6(14.6)$ & 2.5 \\
\hline $\begin{array}{l}\text { In this school, there are enough ramp } \\
\text { and pathways }\end{array}$ & $14(34.1)$ & $8(19.5)$ & $6(14.6)$ & 12(29.3) & $1(2.4)$ & 2.5 \\
\hline $\begin{array}{l}\text { In this school sighted learners read } \\
\text { for learners with VI. }\end{array}$ & $5(12.2)$ & 12(29.3) & $1(2.4)$ & $15(36.6)$ & $8(19.5)$ & 3.2 \\
\hline Overall mean & & & & & & 2.7 \\
\hline
\end{tabular}

KEY: SD-Strongly Disagree, D-Disagree, U-Undecided, A-Agree, SA-Strongly Agree

Table 3. Number of Story Books

\begin{tabular}{llll}
\hline $\begin{array}{l}\text { Number of Story } \\
\text { books }\end{array}$ & Frequency & Percent & Valid Percent \\
\hline 0 & 90 & 66.7 & 66.7 \\
1 & 34 & 25.2 & 25.2 \\
2 & 8 & 5.9 & 5.9 \\
3 & 3 & 2.2 & 2.2 \\
Total & 147 & 100.0 & 100.0 \\
\hline
\end{tabular}

\section{Relationship between Environment and Learners Performance}

In order to establish the relationship between learning resources/material and learners performance, first, learners were asked to indicate the number of storybooks they read with respect to the availability of these books in Braille in school and teachers efforts to encourage them read the books. The results were presented in table 3 as shown above.

The results in table 3 indicate that majority of the learners $90(66.7 \%)$ did not read books at all, $34(25.2 \%)$ read one book in a week, $8(5.9 \%$ ) read 2 books in a week, and $3(2.2 \%)$ read 3 books in a week. In this case, scarcity of reading is largely dependent on the availability of the books in the school, which in turn contributes to a better environment for learners in school. This is an indication that the school environment was of a significant challenge to learners with $\mathrm{VI}$.

\section{CONCLUSION AND RECOMMENDATIONS}

\section{CONCLUSIONS}

Based on the findings of the present research, the study made the following conclusions:

Attitude is a significant factor towards learner's 
acquisition of English Braille grade II skills and performance. Negative attitude has negative reputation towards learner's ability to read and write English Braille grade II. As per the results, learners perform poorly due to negative attitude. Therefore learners have a negative attitude towards reading and writing English Braille Grade II in the selected special primary schools.

Environment based challenges are a key to determining learner's ability to respond positively to skill acquisition. Poor environment which cannot accommodate learners with disability is a direct cause of poor performance, while inclusive or child friendly environment has a positive implication towards better learning and the consequences are good academic performance. This can be drawn from the current study findings, whereby the state of poor school setting such as poor planning, leading to lack of ramps and good pathways makes the environment inconclusive to learners with visual impairment to comprehend educational instructions. This could be a significant cause to learner's inability to read and write English Braille grade II since the environment is unfriendly to learners with VI.

\section{RECOMMENDATIONS}

Based on the study findings, a few recommendations were made:

The study highly recommends that learners be introduced to English Braille grade II, at an early stage so as to create positive attitude towards the same.

The Ministry of Education and other education stakeholders should heavily invest on Inclusive Education to achieve an ideal School for all round learning environment: thus; a disability-friendly environment; adequate, qualified human resource (educators and the paramedics) as well as the critical non-human resources like learning materials for learners with visual impairment.

\section{Suggestion for Further Studies}

i). The study established that negative attitude of learners with VI had an influence on learners' ability to read and write English Braille grade II. The study therefore suggests further studies to be carried out on the causes of negative attitude among learners with $\mathrm{VI}$ towards Braille grade II.

\section{REFERENCES}

Abilu RA (2004). Tools for enhancing English Braille notation skills of teachers and service providers. J. Assoc. Libr. Vis. Impair. 3(1): 18 - 28.Abledata (2004). Fact sheet on Braille writers, printers and software. Retrieved from http://www.abledata.com/abledata doc/ Braille_Writers_printers_software.htm
Amato S (2002) Standards for competence in Braille literacy skills in teacher preparation programmes: J. Vis. Impair. Blindness 96(3):143-153

American Printing House for the blind (2007). Annual report Louis Author.

Atinmo MI (2000). Availability and accessibility of library resources for the visually handicapped in Nigeria: The way forward. J. Assoc. Libr. Vis. Handicap. 1 (1): 15-22.

Basharu D (2000). The state of Braille literacy in Nigeria, paper represented in the international symposium on Braille in age of digitization, Copenhagen, Denmark. Federal ministry of education, (1981) national policy on education.lagos, Nigeria; government press.

Best JW, Kahn JV (2006). single subject experimental research in education, 7th ed. Prentice hall of India, N.Delhi, 165-180

Biglow A (2005). Blindness in Hopkins $\mathrm{B}(\mathrm{Ed})$, the comb ridge encyclopedia of child development (pp.409-413).New York Combridge University press.

Boets B, Wouters J, De Smedt B, Ghesquire P (2008). Modeling relations between Sensory processing, speech perception, orthographic and phonological ability, and literacy achievements: Brain and language. 106; 29-40.

Bram M (2007). Divergent of development of verbal skills in children who are blind or sighted. J. Vis. Impair. Blindness, 102; 212-225.

Daily Nation (2011, December 18). Kenya' richest and poorest counties. Daily Nation Nairobi, 1770, 1-4.

Connel T (2003). Braille wring for students who will graduate 2015 . $\mathrm{Http} / \mathrm{ww} . t s b r i e d u / s e e$ hear/fal $03 / \mathrm{bBraille} . \mathrm{htm}$

Cop pins N, Barlow F (2006). Reading difficulties in blind, Braille reading children. Br. J. Vis. Impair. 23: 1-11.

Corn \& Koening (2002). Literacy for students with low vision; A frame work for delivering instruction: J. Vis. Impair. Blindness. 1(96):305-322

Daily Nation (2014). Inside the world's first Braille Cellphone, Daily Nation News Paper Kenya.

Danielson \& Lamb (2006). Beginning reading/writing for Braille or print readers. A teacher guide to psycholinguistic viewpoint Melbourne: Royal Victoria Institute for the blind.

Dodd B, Conn L (2000). The affects of Braille orthography on blind children'sPhonological, awareness skills of children who are blind. J. Vis. Impair. Blindness. 96: 38-49

Erickson KA, Hatten D (2007). Literacy and Visual Impairment: Seminars in speech and language.28 (1): 58-68.

Gerber \& Smith, B.C. (2006). Literacy and controversy: focus group data from Canada proposed changes to Braille code. J. Vis. Impair. Blindness. 100: 459-470.

Harisson JR, Craig G (2003). Using distance education for family to improve children Braille literacy. J. Vis. Impair. Blindness. 97(3).

Hatlen P (2000). Historical perspectives. In M. C. Holbrook \& A. J. Koenig (Eds.,), Foundations of Education: History and Theory of Teaching Children and Youths with Visual Impairments. New York: American Foundation for the Blind.

Healy (2004). Mult-literacy pedagogy in practicing primary, Vol.9, ALBEA.

Hehir T (2002). Eliminating Albinism in Education . Harvard Educ. Rev. 72(1):1-32

Herberg T, Stough L, Clark J (2004).Teaching and assessing the appropriateness subcontracted Braille. Pp.123-134

Hong S, Erin JN (2004). The impact of early exposure to uncontracted Braille reading on students with visual impairment, Journal of Visual impairment and Blindness, 98(6)

Johnson W, Baldwin M (2006). Labor Market Discrimination against Men with disabilities in the year of the ADA. Southern Econ. J. 66(3): 548

Okoth D, Eron L, Kutosi GW (2000). Distance learning special Needs education Module Nairobi, KISE

Kenya National Bureau of Statistics (2009). The 2009 Kenya Population and Housing Census.

Kiumbuki M (2014, may 23). Technology in Brief. Daily Nation Nairobi, 17947.MOE.

MoE ( 2003). Report on Special Needs Education: appraisal Exercise, Nairobi, Kenya. 
Koening \& Holbrook (2000). Assuring quality instructions in Braille literacy programme: J. Vis. Impair. Blindness. 2(94): 650-658.

Lex GL (2009). The educator.Journal of Braille literacy via XX11, (22) p 16.International council for for Education of the people with visual impairment (ICEVI). India Judd Street

Mason J (2000). Shortages of personal in the low vision incidence: Area of blindness. Working and planning together. Teaching exceptional Children, no. p 91

Millar's (2003). Reading by touch .New York: Routledge.

Miller C, Rash A (2001). Reading for everyone: Expanding Braille literacy options see/hear 6: $\mathrm{p}$ 22-26.

Miller HH (2000). The music code, in J.Doxon (ed), Braille in to the next millennium: (pp-128-151): National library services for Blind and physically handicapped individuals in North American, Washington, DC.

Mugenda OM, Mugenda GA (2003). Research Methods Qualitative and Quantitative Approaches. Nairobi: African Centre for Technological Studies

Mwaura M, Mweru J (2010). Basic English Braille, Nairobi, Kenya Institute of Special Education.

National Reading Panel (2001). Teaching children to read. Retrieved on February 9, 2005 from http:// www. National reading panel org/ publication summary $\mathrm{htm}$

Pressley M (2005). Reading instructions that works: The case for balanced teaching $3^{\text {rd }} E d$. New York: Guilford press.

Riccobono MA (2006). "Significanceof the Braille on the blind: A review and Analysis of Research Based Literature "unpublished paper, John Hopkins University.

Sadato N (2005). How the blind "see "Braille: Lessons from functional magnetic resonance imaging. The neuroscientist, 11: 577-582.

Spungin SJ (2000). Braille and Beyond: Braille literacy in a larger contest. J. Vis. Impair. Blindness. 6: 3.90w
Spungin $\mathrm{R}$ (2003). The "cannibalism is a line and well in the blindness field ". J. Vis. Impair. Blindness. 97(2): 69-71.

Stein J (2001).The magnocellular theory of developmental dyslexia: Dyslexia, 7, 12-36.

Swenson A, M \&D. Andrea in (2006), The Braille trail: journal of visual impairment and Blindness New York AFB.Vol.2 p.38-41.

Wall Emerson R, Holbrook FM (2009). Acquisition of literacy skills by young childrenwho are blind: Results from ABC Braille study. J. Vis. Impair. Blindness, 103:610-624.

Whitehurst GJ (2003). Classroom literacy environment checklist. New York: The National

centre for learning disabilities, retrieved from htt: // www, get ready to read. Org/pdfs/ School environs scan pdf.

Yibeltal K (2012). Braille in Ethiopia, Challenges and Challenges. The Educator: Braille, vol.1, pp 30-32, Icevi secretariat professor's colony S.R.K Vidyalaya post Coimbatore 641020 Tamil Naidu, India.

Young, Gill on G (2001). Phonological awareness training for the Blind: Instruction manual. Christchurch, Newzeal and: Department of speech and therapy, University of Canterbury.

Zurita P (2009). Braille wonder and some myths. The Educator: Braille literacy, vol.xxii, 1, pp 16-17.the International Council for Education of People with visual impairment no. 3 professor's colony palamalai Road, S, R, K.Vidyalaya Postcoimbatore641020 Tamil Nadu, and India. 